\title{
ISOLDE target and ion source chemistry
}

\author{
U. Köster for the ISOLDE Collaboration
}

CERN, ISOLDE, 1211 Genève 23, Switzerland

(Received January 10, 2001; accepted April 23, 2001)

ISOL system / radioactive ion beams / chemical separation / targets / ion sources / ISOLDE

\section{Summary}

For the production of radioactive ion beams by means of the ISOL (isotope separation on-line) method in which the nuclei of interest are stopped in a thick target, chemistry plays a crucial role. It serves to separate the nuclear reaction products in atomic or molecular form from the bulk target and to transfer them efficiently to an ion source. This article gives an overview of ISOLDE radiochemical methods where targets (liquid metals, solid metals, carbides and oxides) and ion sources are optimized with respect to efficiency, speed and chemical selectivity. Rather pure beams of nonmetals and volatile metals can be obtained with a

temperature-controlled transfer line acting as thermo-

chromatograph. For less volatile metals the temperature of the target and ion source units needs to be kept as high as possible, but a selective ion source can be used: positive surface ionization for metals with ionization potentials below about $6 \mathrm{eV}$ and the RILIS (resonance ionization laser ion source) technique for most other metals.

\section{Introduction}

ISOL (isotope separation on-line) facilities provide a large variety of radioactive ion beams for a multitude of applications. For an optimum use, these beams have not only to be intense, but also as pure as possible. As a general rule, the retention of beam contaminants should be done as early as possible in the separation chain: production method - target - transfer line - ion source - mass separator - experiment. Especially when using high-energy particles as primary beam the isobaric distribution of the produced nuclides is very wide. To provide isotopically pure beams it is therefore of utmost importance to include chemically selective steps already inside the target and ion source unit. In the following these steps will be discussed individually.

\section{Target}

In "thin target" ISOL facilities (e.g. GSI ISOL) the functions of the production target and the recoil catcher can be separated and thus allow a wide choice of catcher materials $[1,2]$. Also facilities using the fragmentation of a heavy ion beam (e.g. SPIRAL [3]) give some freedom in the choice of the target material. However, in "thick target" ISOL facilities using high energy protons as primary beam (1.0 and $1.4 \mathrm{GeV}$ at ISOLDE), the choice of the target material is guided by the simultaneous optimization of the production rate in the target and the release efficiency from the target. The production via spallation or fragmentation requires a target heavier than the desired element (i.e. $Z_{\text {target }}>$ $Z_{\text {product }}$ and $N_{\text {target }} \geq N_{\text {product }}$ ). The highest cross-sections of (mainly neutron-deficient) spallation products are obtained for a close-by target nucleus (i.e. $Z_{\text {product }} \approx Z_{\text {target }}$ and $N_{\text {product }} \approx N_{\text {target }}$ ).

Neutron-rich nuclei of medium mass (about $60 \lesssim A \lesssim 170$ ) are mainly produced in fission of actinides. Actinide targets are moreover required for the production of heavier nuclei ( $Z \geq 82, N \geq 126$ ) and they provide high cross-sections for the production of light neutron-rich nuclei (e.g. heavy sodium isotopes).

The electronic stopping power of $1 \mathrm{GeV}$ protons is about $(3-4) \times Z \mathrm{MeV}$ per $\mathrm{mol} / \mathrm{cm}^{2}$ target thickness and the range about $200 / Z \mathrm{~mol} / \mathrm{cm}^{2}$. Thus dense heavy targets with up to about $50 \mathrm{~cm}$ length could be used. However, the production cross-sections of many of the exotic nuclides increase strongly with proton beam energy. Therefore it does not make sense to stop the protons completely, but instead "thinner" targets are used where the protons lose only some $100 \mathrm{MeV}$ during passage. Moreover a very long target would increase the effusion path and thus the delay losses of shortlived nuclei. A standard ISOLDE target container is made from a tantalum cylinder with $20 \mathrm{~cm}$ length and $2 \mathrm{~cm}$ diameter. By ohmic heating with up to $1000 \mathrm{~A}$ it can be brought up to $2500{ }^{\circ} \mathrm{C}$. The only orifice of the target container is connected via a transfer line to the ion source. Provided a sufficiently high temperature is maintained, most produced radio-nuclides will arrive sooner or later in the ion source if they did not decay before.

Often the same or neighboring target elements can be used in different chemical forms. The choice is made to optimize for a fast release of the desired elements and as far as possible a suppression of isobaric contaminants. 


\section{Molten metal targets}

The highest target density can be obtained with bulk material. The target thickness is just given by the product of target length and natural density of the material. To allow for a reasonably fast release of the produced nuclei despite the close packing, the target is kept in a molten state. Normally elements melting at relatively low temperatures are used: tin, lanthanum and lead. Also liquid germanium, bismuth, gold and several other elements and alloys have been employed successfully.

Table 1. Overview of molten metal targets used at ISOLDE. The molten uranium target was not yet used on-line at ISOLDE, but is given as an outlook. $\vartheta_{\mathrm{m}}$ is the melting point of the target material and $\vartheta_{\max }$ the maximum operation temperature. $p_{\text {vap }}$ is the vapor pressure (from $[4,5,6])$ and $\rho$ the bulk density at $\vartheta_{\max } . \zeta$ is the target thickness at $20 \mathrm{~cm}$ length and $\vartheta_{\max }$. The references give obtained yields and details for each target.

\begin{tabular}{|c|c|c|c|c|c|c|c|}
\hline El. & $\begin{array}{l}\vartheta_{m} \\
{ }^{\circ} \mathrm{C}\end{array}$ & $\begin{array}{c}\vartheta_{\max } \\
{ }^{\circ} \mathrm{C}\end{array}$ & $\begin{array}{l}p_{\text {vap }} \\
\text { mbar }\end{array}$ & $\begin{array}{c}\rho \\
\mathrm{g} / \mathrm{cm}^{3}\end{array}$ & $\begin{array}{c}\zeta \\
\mathrm{g} / \mathrm{cm}^{2}\end{array}$ & $\begin{array}{c}\text { Typical } \\
\text { isotopes } \\
(a\end{array}$ & Ref. \\
\hline $\mathrm{Ge}$ & 937 & 1100 & $6 \cdot 10^{-5}$ & 5.5 & 110 & ${ }^{60-74} \mathrm{Zn},{ }^{64-75} \mathrm{Ga}$ & {$[7,8]$} \\
\hline $\mathrm{Sn}$ & 232 & 1200 & $7 \cdot 10^{-3}$ & 6.4 & 128 & $97-122 \mathrm{Cd}$ & [9] \\
\hline $\mathrm{La}$ & 920 & 1400 & $10^{-4}$ & 6.2 & 124 & ${ }^{115-128} \mathrm{I},{ }^{115-133} \mathrm{Xe}$ & {$[7,10]$} \\
\hline $\mathrm{Pb}$ & 328 & 800 & $10^{-1}$ & 10.1 & 200 & $177-207 \mathrm{Hg}$ & [12] \\
\hline $\mathrm{Bi}$ & 271 & 600 & $2 \cdot 10^{-3}$ & 9.6 & 190 & ${ }^{177-207} \mathrm{Hg}$ & {$[12]$} \\
\hline $\mathrm{U}$ & 1132 & 1700 & $2 \cdot 10^{-5}$ & 17.6 & $(350)$ & $\mathrm{Kr}, \mathrm{Cd}$, I, etc. & {$[13,14]$} \\
\hline
\end{tabular}

a) Not exhaustive list.

Table 1 gives an overview of typical ISOLDE molten metal targets. It should be noted that the quoted vapor pressures are inside the target. Condensation in the transfer line will reduce it sufficiently to avoid a quenching of the ion source efficiency. Note also that the lists of typical isotopes are not exhaustive. Fragmentation reactions with high energy protons will produce isotopes of all elements from hydrogen to the target. Thus the isotopes of lighter homologues are often also extracted from the same target and ion source unit, however with lower yields corresponding to the reduced production cross-sections.

Due to the high target density molten metal targets can provide the highest intensities for not too short-lived isotopes of certain elements: $\mathrm{Cd}$ from a $\mathrm{Sn}$ target, $\mathrm{Hg}$ from a $\mathrm{Pb}$ target, $\mathrm{Xe}$ and Cs from a La target.

Experiences with other liquid targets (various La-X alloys, a U-Cr alloy and a $\mathrm{ThF}_{4}-\mathrm{LiF}$ mixture) are discussed in [7]. A molten La-Th target was operated around $1300{ }^{\circ} \mathrm{C}$ to produce $\mathrm{Rn}, \mathrm{Fr}$ and $\mathrm{Ra}$ isotopes at ISOLDE SC [15]. Later it was replaced by the ThC/graphite and UC/graphite targets (see below) which give a faster release. A molten gold target was also tested at ISOLDE SC for the production of mercury beams via $\mathrm{Au}\left({ }^{3} \mathrm{He}, \mathrm{p} x \mathrm{n}\right)$ reactions as an alternative to the $\mathrm{Pb}(\mathrm{p}, 3 \mathrm{p} x \mathrm{n})$ reactions [16]. A eutectic mixture of $\mathrm{TeO}_{2}, \mathrm{KCl}$ and $\mathrm{LiCl}$ was used at ISOLDE for the production of elementally pure beams of antimony [17] and molten $\mathrm{Ce}_{3} \mathrm{~S}_{4}$ was tested offline for the release of tellurium isotopes [18]. At the ISOCELE facility also molten targets of other elements and compounds were used: $\mathrm{Ag}, \mathrm{Ce}, \mathrm{Pr}, \mathrm{Nd}, \mathrm{Tb}, \mathrm{Gd}-\mathrm{Cu}, \mathrm{Er}-$ $\mathrm{Cu}, \mathrm{Pt}-\mathrm{B}$ and $\mathrm{ThF}_{4}-\mathrm{NaF}[19,20]$. Arsenic beams were separated from a liquid germanium target at temperatures up to $1570{ }^{\circ} \mathrm{C}$ at the HRIBF facility (Oak Ridge) [21].

There is high interest to use also liquid uranium targets.
However, liquid uranium is very aggressive, attacking practically all possible container materials [7]. Recent experiments at Orsay showed that $\mathrm{Y}_{2} \mathrm{O}_{3}$ can be used as wall material up to $1700{ }^{\circ} \mathrm{C}$ [14].

Normally only volatile elements with a low desorption enthalpy are released from liquid targets - see ref. [22] for calculated desorption enthalpies of most elements from a great variety of molten metal targets. The average release times from liquid targets are typically of the order of minutes [12]. They decrease at higher target temperatures. In general the vapor pressure of the target material sets an upper limit for the usable target temperatures. For higher-melting materials the target is not run to this limit to avoid a reduction of the target lifetime by damage of the target container. Ref. [12] discusses in detail the effects of a pulsed proton beam structure $^{1}$ on the release times and the lifetime of the target container.

\section{Solid metal targets}

Elements with high desorption enthalpy require higher target temperatures for an efficient release. Liquid metal targets can no longer be used due to their excessive vapor pressure and the rapid attack of the container materials. Instead highmelting metals in solid form are used. To keep the diffusion path short ${ }^{2}$, powders or thin foils are used. The standard foil targets are made from a single strip of foil (typically $20 \mu \mathrm{m}$ thick) which is rolled and kept together with a tantalum wire. The foil is embossed to keep some distance between the layers and hinder thermal contact. The cylindrical package is inserted along the length of a tantalum target container. Typical packing fractions are $30-40 \%$, i.e. the average target density is about one third of the bulk density. Table 2 shows an overview of typical ISOLDE metal foil targets.

Table 2. Overview of metal foil targets presently used at ISOLDE. Note that the Ti foil targets are run close to the melting point and can even start to melt locally. For the symbols used see the caption of Table 1. Here, $\rho$ is the bulk density at room temperature.

\begin{tabular}{|c|c|c|c|c|c|c|c|}
\hline El. & $\begin{array}{c}\vartheta_{\mathrm{m}} \\
{ }^{\circ} \mathrm{C}\end{array}$ & $\begin{array}{c}\vartheta_{\text {max }}{ }^{\circ} \mathrm{C} \\
\text { Ti }\end{array}$ & $\begin{array}{c}p_{\text {vap }} \\
\text { mbar }\end{array}$ & $\begin{array}{c}\rho \\
\mathrm{g} / \mathrm{cm}^{3}\end{array}$ & $\begin{array}{c}\zeta \\
\mathrm{g} / \mathrm{cm}^{2}\end{array}$ & $\begin{array}{c}\text { Typical } \\
\text { isotopes }\end{array}$ & Ref. \\
\hline $\mathrm{Ti}$ & 1675 & 1600 & $2 \cdot 10^{-3}$ & 4.5 & 25 & ${ }^{37-46} \mathrm{Ca},{ }^{42-48} \mathrm{Sc}$ & {$[23]$} \\
$\mathrm{Nb}$ & 2470 & 2050 & $3 \cdot 10^{-6}$ & 8.6 & 50 & $\begin{array}{c}70-85 \\
{ }^{76 r}{ }^{70-85}{ }^{70-87} \mathrm{Kr}^{74-86} \mathrm{Rb}\end{array}$ & {$[24,25]$} \\
$\mathrm{Ta}$ & 2996 & 2200 & $5 \cdot 10^{-7}$ & 16.7 & 110 & $\begin{array}{c}{ }^{79-89} \mathrm{Y}, \text { etc. } \\
\text { many }\end{array}$ & {$[23,26]$} \\
$\mathrm{W}$ & 3410 & 2200 & $5 \cdot 10^{-8}$ & 19.3 & $7^{(a}$ & test: $^{8,9,11} \mathrm{Li}$ & \\
\hline
\end{tabular}

a) This target had a very compact geometry: only $7 \mathrm{~mm}$ in diameter and $50 \mathrm{~mm}$ long.

A tantalum target developed to dissipate the $25 \mathrm{~kW}$ deposited by a $100 \mu \mathrm{A}, 800 \mathrm{MeV}$ proton beam was proposed for the RIST (Radioactive Ion Source Test) project in the UK. Its construction of 6000 disks with $25 \mu \mathrm{m}$ thickness diffusion bonded alternately with washers and radiator fins

\footnotetext{
1 Note that a standard proton beam at ISOLDE PSB has up to $5 \mu \mathrm{C}$ of protons within $2.4 \mu \mathrm{s}$, thus depositing a peak power of up to $25 \mathrm{MW}$ per $\mathrm{cm}$ length in a lead target!

2 The diffusion coefficient in solid metals is typically some orders of magnitude smaller than in liquid metals. However, the smaller dimensions ( $\sim \mu$ m instead of $\mathrm{cm}$ ) normally overcompensate this drawback.
} 
was also optimized for minimum effusion time [28]. Tests at ISOLDE showed improvements for the release of certain species [29].

"Thin foil targets" made from 200 sheets of only $2 \mu \mathrm{m}$ thick Ta foil were successfully used for the rapid release of very short-lived isotopes $\left({ }^{11} \mathrm{Li},{ }^{12} \mathrm{Be}\right.$ and $\left.{ }^{14} \mathrm{Be}\right)$, thus reducing the decay losses and increasing the yields by more than an order of magnitude [30, 31].

With high-energy protons the production cross-sections for most spallation products from $\mathrm{Zr}$, Nb or Mo are comparable. At ISOLDE only niobium foil targets are used since niobium has a lower vapor pressure than zirconium or molybdenum at a given temperature. Moreover the diffusion of several elements was found to be faster in $\mathrm{Nb}$ compared with Mo (e.g. twenty times faster for Se at equal temperature) [18]. Beyer et al. [32] found at equal temperature the release of $\mathrm{Rb}, \mathrm{Sr}$ and $\mathrm{Y}$ to be fastest in $\mathrm{Zr}$, followed by $\mathrm{Nb}$ and then Mo. In fact, at TISOL a zirconium foil target gave higher yields for most isotopes than a niobium foil target [33].

Metal powder targets ( $\mathrm{V}, \mathrm{Nb}, \mathrm{Mo}, \mathrm{Hf}, \mathrm{Ta}, \mathrm{W}, \mathrm{Ir})$ [18] were studied off-line and partly used on-line at ISOLDE [8, 27] and deposited metal layers from Si, V, Mo, Ta, Ir, Th and $\mathrm{U}$ were used at the PS on-line separator [34, 35]. Bjørnstad et al. report on the use of a mixed $\mathrm{Th} / \mathrm{Nb}$ powder target at ISOLDE [8]. The release from other metals ( $\mathrm{Ru}, \mathrm{Re}, \mathrm{Os})$, such as pure powder or mixed with graphite powder, was studied off-line [17].

$\mathrm{Sn}$ - and Pt/graphite powder mixtures were heated above the melting point of the metal, thus giving a target structure which is something in between a solid and a liquid target. The target element is kept in a liquid phase, but the admixture of graphite powder assures a reduced diffusion length in the bulk material. With this method beams of short-lived cadmium isotopes were separated from the $\mathrm{Sn} /$ graphite target at $1000{ }^{\circ} \mathrm{C}$ and gold beams from the Pt/graphite target at up to $1900{ }^{\circ} \mathrm{C}$ [23].

Still, there are many target elements which, in metallic state, are difficult to keep stable at high temperatures. They tend to react with the container material or the metal foils fuse together, increasing the diffusion path. Moreover, some elements show a very slow diffusion in solid metals. In those cases refractory compounds like carbides, oxides, etc. have to be used as target material.

\section{Carbides}

Some metals form very stable carbides: actinides, lanthanides, titanium, chromium, etc. Here, it is not the melting point of the target material which limits the operation temperature, but the vapor pressure of impurities and of the metal component. Decomposition of the compound is indicated in Table 3 by a melting point in parentheses.

$\mathrm{ScC}_{2}$-graphite targets were used at ISOLDE SC for the production of neutron-deficient sodium, magnesium, aluminum [42] and potassium isotopes [8] and a $\mathrm{CaC}_{2}$ target was used at INS for the production of neutron-deficient potassium isotopes [43]. Moreover off-line release studies were performed with TiC/graphite and $\mathrm{ZrC} /$ graphite [17]. At TISOL $\mathrm{ZrC}$ targets were used for the production of various alkaline
Table 3. Overview of carbide targets used at ISOLDE. For the symbols used see the caption of Table 1. $p_{\text {vap }}\left(\mathrm{LaC}_{2}\right)$ is the sum of all evaporated compounds, taken from [36]. $\rho$ is the bulk density of the pure carbide, but in fact most of the materials are mixed with graphite to obtain a molar ratio of 1:4 to 1:10 between metal and carbon. See the references for the detailes composition. $\zeta$ gives the effective thickness of the metal content.

\begin{tabular}{|c|c|c|c|c|c|c|c|}
\hline 1. & $\begin{array}{l}\vartheta_{\mathrm{m}} \\
{ }^{\circ} \mathrm{C}\end{array}$ & $\begin{array}{l}\vartheta_{\max } \\
{ }^{\circ} \mathrm{C}\end{array}$ & $\begin{array}{l}p_{\text {vap }} \\
\text { mbar }\end{array}$ & $\begin{array}{c}\rho \\
\mathrm{g} / \mathrm{cm}^{3}\end{array}$ & $\begin{array}{c}\zeta \\
\mathrm{g} / \mathrm{cm}^{2}\end{array}$ & & \\
\hline C & 3600 & $1800^{(a}$ & $2 \cdot 10$ & 2.5 & $73^{(b}$ & & \\
\hline $\mathrm{Al}_{4} \mathrm{C}_{3}$ & (1400) & 1200 & {$\left[4 \cdot 10^{-4}\right.$} & 2.4 & 21 & ${ }^{20-24} \mathrm{Na}$ & \\
\hline $\mathrm{SiC}$ & $(2300)$ & 1200 & (c & 3.2 & 21 & $\mid \begin{array}{l}{ }^{17-23} \mathrm{~F},{ }^{18-24} \mathrm{Ne} \\
{ }^{20-24} \mathrm{Na},{ }^{22-28} \mathrm{Mg}\end{array}$ & \\
\hline $\mathrm{VC}^{(d}$ & 2810 & 2000 & $10^{-3}$ & 5.8 & 38 & ${ }^{32-46} \mathrm{Ar}$ & \\
\hline $\mathrm{LaC}_{2}$ & ? & 1750 & $2 \cdot 10^{-3}$ & 5.0 & $\approx 30$ & $\mid \begin{array}{l}9^{98} \mathrm{Cd},{ }^{100-114} \mathrm{In} \\
{ }^{104-}{ }^{-} \mathrm{Sn},{ }^{114-138} \mathrm{Cs}\end{array}$ & \\
\hline & 2450 & 200 & $2 \cdot 10$ & 9.0 & $\approx 50$ & & \\
\hline $\mathrm{C}_{2}$ & $\approx 2450$ & 200 & $2 \cdot 10^{-}$ & 11.3 & $\approx 50$ & na & \\
\hline
\end{tabular}

a) The temperature was not limited by the target, but by the maximum current of the target power supply.

b) A $400 \mathrm{~mm}$ long target was used.

c) The temperature was not limited by the vapor pressure of $\mathrm{SiC}$, but by that of impurities (mainly $\mathrm{SiO}$ and $\mathrm{Al}$ ).

d) VC was longtime used at ISOLDE SC to produce argon isotopes, but today $\mathrm{CaO}$ targets are used instead which give higher yields [41].

isotopes [33]. At IRIS a $\mathrm{GdC}_{x}$ /graphite target was used for production of $\mathrm{In}, \mathrm{Cs}$ and $\mathrm{Eu}[44]$ and even a $\mathrm{CmC}_{x}$ /graphite target was tested [45].

\section{Oxides}

Oxide targets are routinely used at ISOLDE, mainly for the production of various noble gas nuclides. Table 4 shows an overview $^{3}$. To avoid an oxidation of the tantalum target container by direct contact with the target material, the latter is normally inserted in a boat made from thin platinum or rhenium foil.

Table 4. Overview of oxide targets used at ISOLDE. For the symbols used see the caption of Table 1. $\vartheta_{\mathrm{m}}$ was taken from [48]. $\rho$ is the density of the bulk material without porosity. Depending on the preparation method the real stochiometry might deviate from the tabulated one.

\begin{tabular}{|c|c|c|c|c|c|c|c|}
\hline El. & $\begin{array}{l}\vartheta_{\mathrm{m}} \\
{ }^{\circ} \mathrm{C}\end{array}$ & $\begin{array}{c}\theta_{\max } \\
{ }^{\circ} \mathrm{C}\end{array} \mid$ & $\begin{array}{l}p_{\text {vap }} \\
\text { mbar }\end{array}$ & $\begin{array}{c}\rho \\
\mathrm{g} / \mathrm{cm}^{3}\end{array}$ & $\begin{array}{l}\zeta \\
\mathrm{g} / \mathrm{cm}^{2}\end{array}$ & $\begin{array}{l}\text { Typical } \\
\text { isotopes }\end{array}$ & Ref. \\
\hline $\mathrm{MgO}$ & 2800 & 1500 & $5 \cdot 10^{-3}$ & 3.6 & 2.9 & ${ }^{17-24} \mathrm{Ne}$ & [41] \\
\hline $\mathrm{Al}_{2} \mathrm{O}_{3}$ & 2050 & 1550 & $4 \cdot 10^{-4}$ & 4.0 & 9 & ${ }^{20-25} \mathrm{Na}$ & \\
\hline $\mathrm{CaO}$ & 2600 & 1400 & $\approx 10^{-4}$ & 3.3 & 5 & $\mathrm{He}, \mathrm{C}, \mathrm{N}, \mathrm{Ne}, \mathrm{Ar}$ & [41] \\
\hline $\mathrm{TiO}_{2}$ & 1850 & 1500 & $3 \cdot 10^{-4}$ & 4.2 & 8.3 & ${ }^{39} \mathrm{Ar}$ and others & [49] \\
\hline $\mathrm{SrO}$ & 2450 & 1500 & $\approx 10^{-4}$ & 4.7 & 18 & ${ }^{72-81} \mathrm{Kr}$ & \\
\hline $\mathrm{ZrO}_{2}$ & 2700 & 1850 & $\approx 10^{-4}$ & 5.9 & 6 & $\mid \begin{array}{c}\mathrm{Mn}, \mathrm{Zn}, \mathrm{Se}, \mathrm{Kr} \text {, etc } \\
56-71 \mathrm{Cu},{ }^{62-74} \mathrm{Ga}\end{array}$ & $\begin{array}{c}{[17,23]} \\
{[39]}\end{array}$ \\
\hline $\mathrm{BaO}$ & 1920 & 1100 & $\approx 10^{-3}$ & 5.7 & 20 & & [10] \\
\hline $\mathrm{La}_{2} \mathrm{O}_{3}$ & 2300 & 1300 & $\approx 10^{-4}$ & 6.5 & $64^{(a}$ & ${ }^{115-125} \mathrm{Xe}$ & \\
\hline $\mathrm{CeO}_{2}$ & 2600 & 1300 & $<10^{-4}$ & 7.1 & 16 & ${ }^{112-125} \mathrm{Xe}$, etc. & \\
\hline $\mathrm{ThO}_{2}$ & 3050 & 2100 & $2 \cdot 10^{-4}$ & 9.9 & $<30$ & many & [17] \\
\hline
\end{tabular}

a) A $400 \mathrm{~mm}$ long target was used.

Among the actinides, especially uranium and thorium form stable oxides. Thoria $\left(\mathrm{ThO}_{2}\right)$ is more stable at higher temperatures ${ }^{4}$ and therefore preferable. Thorium oxide powder

\footnotetext{
3 Initially at ISOLDE hydrated oxide targets were used at low temperature (only heated by the proton beam) [46, 47].

4 Urania has at $2100^{\circ} \mathrm{C}$ already a vapor pressure of $6 \cdot 10^{-2}$ mbar.
} 


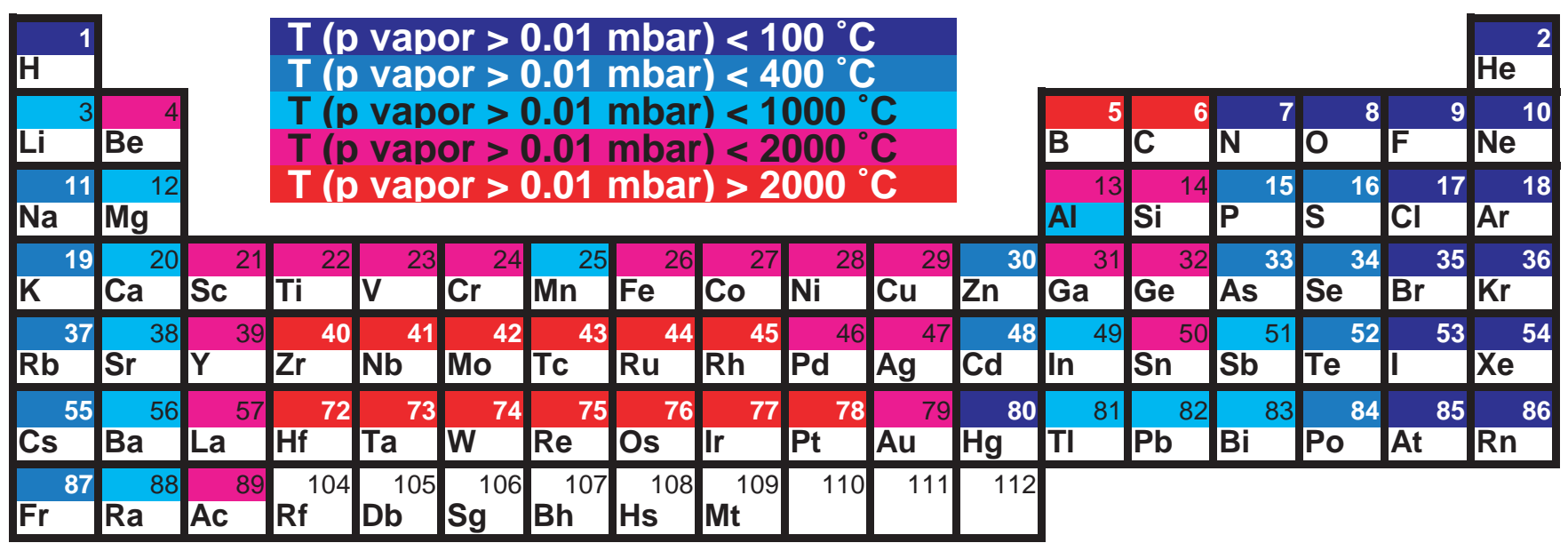

\begin{tabular}{|c|c|c|c|c|c|c|c|c|c|c|c|c|c|}
\hline & & & & & & & & & & 68 & 69 & 70 & \\
\hline $\mathrm{Ce}$ & $\mathbf{P r}$ & Nd & Pm & Sm & Eu & Gd & Tb & Dy & Ho & Er & Tm & $\mathrm{Yb}$ & Lu \\
\hline Th & $\mathrm{Pa}^{9}$ & U & $\mathrm{Np}$ & $\mathrm{Pu}$ & Am & $\mathrm{Cm}$ & $\mathrm{Bk}^{9}$ & $\mathrm{Cf}^{9}$ & $\mathrm{Es}^{99}$ & $\mathrm{Fm}^{100}$ & $\mathrm{Md}^{101}$ & ${ }^{102}$ & $\mathrm{Lr}^{103}$ \\
\hline
\end{tabular}

Fig. 1. Indication for the volatility of the elements, presented by the temperature where the vapor pressure of the element attains $0.01 \mathrm{mbar}$.

targets have already been used at ISOLDE and showed a rapid release of noble gases [42], but had the tendency to sinter within some hours at operational temperature.

Most ISOLDE oxide targets are either made by sintering commercially available oxide powders or by decomposing carbonates under vacuum [41]. Particularly interesting are oxides which are commercially available in form of felt or cloth $^{5}$. They contain no binders and can be heated to high temperatures without excessive outgassing. The individual fibre diameters range from 5 to $10 \mu \mathrm{m}$ and assure short diffusion paths. The zirconia and ceria targets quoted above are of this type. Alumina, yttria and hafnia are also available in a similar form. However, titania and thoria fibres are not commercially available in this form and were therefore "homemade" via fossilization of an impregnated rayon felt. Obviously oxide matrices will release elements which form volatile oxides particularly rapidly, but delay elements which form refractory oxides [50]. For example the zirconia felt targets showed a fast release ${ }^{6}\left(t_{50} \approx 1\right.$ s) of copper and gallium while the same elements are only very slowly released from $\mathrm{Nb}$ foil targets $\left(t_{50}>100 \mathrm{~s}\right)[39]$.

\section{Other materials}

Off-line release tests of many other refractory compounds are reported in [18] $\left(\mathrm{BaB}_{6}, \mathrm{BaZrO}_{3}, \mathrm{CeB}_{6}\right.$ and $\left.\mathrm{CeS}\right)$ and [17] $\left(\mathrm{Zr}_{5} \mathrm{Ge}_{3}, \mathrm{Hf}_{3} \mathrm{Si}_{2}, \mathrm{Hf}_{5} \mathrm{Ge}_{3}, \mathrm{Hf}_{5} \mathrm{Sn}_{3}\right.$ and $\left.\mathrm{Ta}_{5} \mathrm{Si}_{3}\right) . \mathrm{CaB}_{6}$ was also tested on-line for the release of argon [11].

At Oak Ridge the release of various elements from BN, CeS, $\mathrm{Zr}_{5} \mathrm{Si}_{3}$ and $\mathrm{Zr}_{5} \mathrm{Ge}_{3}$ was measured [51]. TISOL used successfully targets from AlN and from Na-, Ca- and Tl-zeolites for the production of $\mathrm{C}, \mathrm{N}, \mathrm{O}$ and noble gases $[52,53]$.

\footnotetext{
5 Zircar Zirconia Inc., Florida, NY; www.zircarzirconia.com.

6 The time $t_{50}$ indicates how long it takes to release half of the isotopes of a given element produced in a short proton pulse.
}

\section{Transfer line}

For liquid metal targets the temperature of the transfer line (connecting target and ion source) has to be limited, to condense excessive vapor pressure from the target and thus protect the ion source. For most other targets the temperature of the transfer line can be chosen individually. Thus a chemical separation can be achieved by isothermal thermochromatography. Figure 1 shows the temperatures where the vapor pressure of the elements attains 0.01 mbar. While this property is chosen somehow arbitrarily, it gives a first indication of the volatility of the element in question. For a more realistic picture, obviously the desorption enthalpies, etc. have to be considered.

At ISOLDE plasma ion sources with 3 different transfer lines are in use $[8,54]$ :

1. A so-called "hot plasma source" (type MK5) where the tantalum transfer line and the ion source are maintained around $1900{ }^{\circ} \mathrm{C}$. It allows to ionize also less volatile elements, but provides practically no chemical selectivity.

2. In a medium temperature version with "cold transfer line" (types MK3 and MK6) the temperature of the copper transfer line is kept between 200 and $400^{\circ} \mathrm{C}$. It is mainly used in combination with liquid targets to limit the vapor pressure in the ion source and to provide a further suppression of less volatile isobars. In this way very pure beams of zinc (from a liquid germanium target), cadmium (from a liquid tin target) or mercury (from a liquid lead or bismuth target) can be achieved ${ }^{7}$.

3. The so-called "cold plasma source" (type MK7) has a water-cooled copper transfer line kept at about room

\footnotetext{
If the temperature of the transfer line is too high, the isobars indium or thallium will leak through.
} 


\begin{tabular}{|c|c|c|c|c|c|c|c|c|c|c|c|c|c|c|c|c|c|}
\hline H & & & $\begin{array}{l}\text { Ioni } \\
\text { Ion } \\
\text { lon }\end{array}$ & $\begin{array}{l}\text { zatio } \\
\text { zatio } \\
\text { zatio }\end{array}$ & $\begin{array}{l}\text { on po } \\
\text { on po } \\
\text { on po }\end{array}$ & $\begin{array}{l}\text { tent } \\
\text { tenti } \\
\text { tent }\end{array}$ & $\begin{array}{l}\text { al: }< \\
\text { al: } 5 \\
\text { al: } 5\end{array}$ & $\begin{array}{l}5 \mathrm{eV} \\
.0-5 . \\
8-6 .\end{array}$ & $\begin{array}{l}.8 \mathrm{eV} \\
.5 \mathrm{eV}\end{array}$ & & & & & & & & $\mathrm{He}^{2}$ \\
\hline $\mathrm{Li}$ & $\mathrm{Be}^{4}$ & & $\begin{array}{l}\text { Elec } \\
\text { Elec }\end{array}$ & $\begin{array}{l}\text { ctron } \\
\text { ctron }\end{array}$ & 1 affir & $\begin{array}{l}\text { nity: } \\
\text { nity: }\end{array}$ & & $\begin{array}{l}3 \mathrm{eV} \\
5-3\end{array}$ & $0 \mathrm{eV}$ & & & B & c & $\mathrm{N}$ & 0 & & $\mathrm{Ne}^{10}$ \\
\hline & 12 & & Elec & ctron & affir & hitv: & & $9-2$ & $5 \mathrm{eV}$ & & & 13 & 14 & 15 & 16 & 17 & 18 \\
\hline & & 2 & & & & & & & & & & & & & & & \\
\hline K & $\mathrm{Ca}^{<U}$ & $\mathrm{Sc}^{21}$ & $\mathrm{Ti}^{24}$ & v & $\mathrm{Cr}^{24}$ & $\mathrm{Mn}^{25}$ & $\mathrm{Fe}^{26}$ & $\mathrm{Co}^{21}$ & $\mathrm{Ni}^{28}$ & $\mathrm{Cu}{ }^{29}$ & $\mathrm{Zn}$ & $\mathrm{Ga}$ & $\mathrm{Ge}^{32}$ & As & $\mathrm{Se}^{34}$ & $\mathrm{Br}^{35}$ & $\mathbf{K r}^{36}$ \\
\hline 37 & 38 & 39 & 40 & & 42 & 43 & 44 & 45 & 46 & 47 & 48 & 49 & 50 & 51 & 52 & 53 & \\
\hline Rb & $\mathrm{Sr}$ & $Y$ & $\mathrm{Zr}$ & $\mathrm{Nb}$ & Mo & Tc & Ru & $\mathbf{R h}$ & Pd & $\mathrm{Ag}$ & Cd & In & Sn & Sb & $\mathrm{Te}$ & & $\mathrm{Xe}$ \\
\hline & 56 & 57 & 72 & 73 & 74 & 75 & 76 & 77 & 78 & 79 & 80 & 81 & 82 & 83 & 84 & 85 & 86 \\
\hline Cs & $\mathrm{Ba}$ & La & $\mathrm{Hf}$ & $\mathrm{Ta}$ & W & $\operatorname{Re}$ & Os & Ir & Pt & $\mathrm{Au}$ & $\mathrm{Hg}$ & TI & $\mathrm{Pb}$ & $\mathrm{Bi}$ & Po & At & $\mathbf{R n}$ \\
\hline 87 & $\mathrm{Ra}^{88}$ & $\mathrm{AC}^{89}$ & $\mathbf{R f}^{104}$ & $\mathrm{Db}^{105}$ & $\mathrm{Sg}^{106}$ & $\mathrm{Bh}^{107}$ & $\mathrm{Hs}^{108}$ & $\mathrm{Mt}^{109}$ & 110 & 111 & 112 & & & & & & \\
\hline
\end{tabular}

\begin{tabular}{|c|c|c|c|c|c|c|c|c|c|c|c|c|c|}
\hline 58 & 5 & & 61 & 62 & 63 & 64 & 65 & 66 & 67 & 68 & 69 & 70 & \\
\hline Ce & Pr & Nd & Pm & Sm & Eu & Gd & Tb & Dy & Ho & Er & Tm & Yb & Lu \\
\hline 90 & 9 & 9 & 93 & 94 & 95 & 96 & 97 & 98 & 99 & 100 & 101 & 102 & 103 \\
\hline Th & $\mathrm{Pa}$ & U & Np & $\mathrm{Pu}$ & Am & $\mathrm{Cm}$ & Bk & Cf & Es & Fm & Md & No & Lr \\
\hline
\end{tabular}

Fig. 2. Ionization potentials and electron affinities of the elements.

temperature to condense nearly all elements. Thus very pure beams of elements and compounds are obtained which are volatile at room temperature: noble gases, $\mathrm{N}_{2}, \mathrm{CO}$, etc.

To improve the retention of specific elements, the copper tube can be replaced by a different material. For example, sodium glass and quartz tubes were used to hold back cesium and indium and provide "clean" beams of neutron-rich cadmium nuclides [55].

It should be kept in mind that the vapor pressure of the element gives only a very rough indication of the volatility. They might well show a large vapor pressure, but be so reactive that they will not effuse freely through target and transfer line but rather react with most wall materials. This is the case, e.g. with fluorine. On the other hand the formation of molecules can enhance the volatility of certain elements considerably. For example carbon is easily released at low temperatures if $\mathrm{CO}$ is formed.

The thermo-chromatographic methods discussed above are mainly of use for non-metals or rather volatile metals. To release short-lived nuclides of less volatile metals the complete target and ion source unit has to be kept at a temperature as high as possible. Thus most isobars will reach the ion source and the required selectivity has to be assured by a selective ionization method $^{8}$.

\footnotetext{
8 Note that the plasma ion sources of the FEBIAD type [56] used at ISOLDE show some dependence of the ionization efficiency on the mass and the ionization potential of the nuclide to be ionized, but no real chemical selectivity.
}

\section{Selective ion sources}

\section{Surface ionization source}

Elements with a low ionization potential $W_{\mathrm{i}}$ are efficiently surface ionized on the hot surface of a noble metal with high work function $\Phi$. The surface ionization efficiency $\varepsilon_{\text {surface }}$ is described by the Saha-Langmuir equation [57]:

$$
\varepsilon_{\text {surface }}=\frac{1}{1+\frac{g_{0}}{g_{+}} \exp \left(\frac{W_{\mathrm{i}}-\Phi}{k T}\right)}
$$

with $g_{+/ 0}=2 J_{+/ 0}+1$ the statistical weights of the ionic and atomic ground state respectively ${ }^{9}$. At ISOLDE typically tungsten tubes $(\Phi \approx 4.5 \mathrm{eV})$ at up to $2400{ }^{\circ} \mathrm{C}$ are used.

This method is particularly efficient $\left(\varepsilon_{\text {surface }} \gg 10 \%\right)$ for alkali metals and for molecules with low ionization potential (e.g. $\mathrm{SrF}$ and $\mathrm{BaF}$ with $W_{\mathrm{i}}=4.9 \mathrm{eV}$ both [58]). For higher ionization potentials the efficiency drops significantly $\left(\varepsilon_{\text {surface }}\left(W_{\mathrm{i}}=6 \mathrm{eV}\right) \approx 1 \%\right)$, i.e. elements with low ionization potential are selectively ionized and isobars with higher ionization potential are efficiently suppressed. However, in reality the selectivity will be lower than suggested by equation 1 due to the so-called "hot-cavity-effect" which can cause a significant increase of the effective ionization efficiency, see [59] and references therein for a detailed discussion.

The analogous process of negative surface ionization happens when elements with high electron affinity $A_{\mathrm{E}}$ hit the hot surface of a material with low work function $\Phi$. The sur-

\footnotetext{
For example $g_{0}=2$ and $g_{+}=1$ for alkalis $\left({ }^{2} S_{1 / 2}\right.$ atomic ground state and ${ }^{1} S_{0}$ ionic ground state).
} 


\section{elements ionized with ISOLDE RILIS}

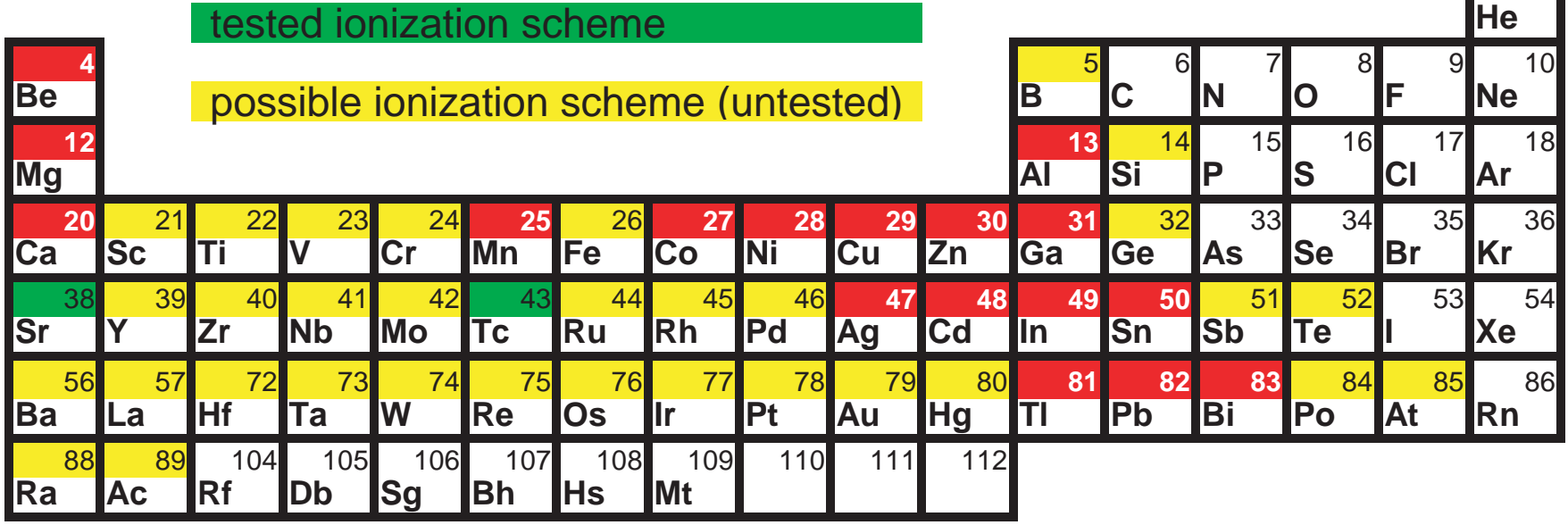

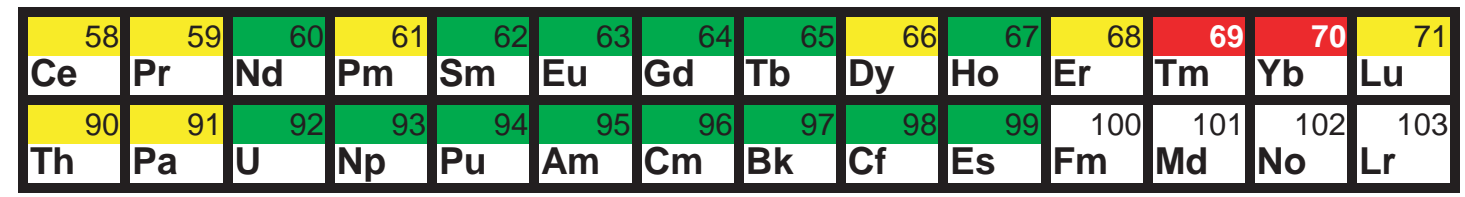

Fig. 3. Elements which were already ionized with the ISOLDE RILIS or where suitable ionization schemes are known or expected.

face ionization efficiency is now given by:

$$
\varepsilon_{\text {surface }}=\frac{1}{1+\frac{g_{0}}{g_{-}} \exp \left(\frac{\Phi-A_{\mathrm{E}}}{k T}\right)}
$$

with $g_{-}$the statistical weight of the negative ion. The ISOLDE negative surface ionization sources (type MK4) with a $\mathrm{LaB}_{6}$ surface $\left(A_{\mathrm{E}} \approx 2.6 \mathrm{eV}\right)$ kept at around $1200^{\circ} \mathrm{C}$ can provide high efficiencies $\left(\varepsilon_{\text {surface }} \gg 10 \%\right)$ for $\mathrm{Cl}, \mathrm{Br}$ and I $[24,60]$, but are very sensitive to a surface poisoning (e.g. by $\mathrm{CO}$ emitted from targets containing graphite) which can significantly alter the effective work function.

Figure 2 shows the elements with low ionization potential or high electron affinity which are more or less compatible with surface ion sources ${ }^{10}$.

\section{Resonance ionization laser ion source}

Still, for most of the less volatile metals with high ionization potential (above $\approx 6 \mathrm{eV}$ ) another selective ionization method is required. This can be provided by a resonance ionization laser ion source (RILIS). The latter uses laser light, which is tuned to the characteristic transitions in the atomic level scheme of the desired element. Up to now ionization schemes for 20 different elements were applied at the ISOLDE RILIS with ionization efficiencies of about 130[61], see Figure 3. With the presently used technique (dye lasers pumped by copper vapor lasers) laser beams with suitable wavelengths could be provided for resonance ionization of practically all metallic elements [39]. Note that a RILIS can not only separate between different elements or isotopes,

10 Note that fluorine is very reactive and thus not compatible to a standard negative surface ionization source. but in certain cases even between isomers of a given isotope by tuning a small bandwidth laser to the hyperfine structure of the desired isomer [62].

The intrinsic selectivity, i.e. the ratio between resonant and non-resonant laser ionization efficiency is extremely high (normally $>10000$ ). However, to obtain a good ion source efficiency the atoms need to be confined in a certain region to interact with the laser light. This is done by a cavity made from a (metal) tube, typically $3 \mathrm{~mm}$ in diameter and some $\mathrm{cm}$ long. To avoid excessive wall sticking times of the nuclides, this cavity is kept at a high temperature (of the order of $2000{ }^{\circ} \mathrm{C}$ or above). Unfortunately, as discussed before, this hot cavity will just act as an excellent surface ionization source. Thus the effective selectivity, i.e. the ratio of laser ionized nuclides to surface ionized isobars may be reduced significantly. The development of laser ion source cavities dedicated to reduce the surface ionized background is under way. A material needs to be found which does not cause too long sticking and which keeps its low work function over sufficiently long time of operation (days) even in combination with targets which might outgas e.g. CO. Among the tested materials $\operatorname{TaC}(\Phi \approx 2.2 \mathrm{eV})$ gave the best selectivity [63], but the longterm stability is not yet satisfactory. Further promising candidates which remain to be tested are, e.g. $\mathrm{ZrC}$ $(\Phi \approx 2.2 \mathrm{eV}), \operatorname{Ir}_{5} \mathrm{Ce}(\Phi \approx 2.7 \mathrm{eV})$ or $\mathrm{CeO}_{2}(\Phi \approx 2.3 \mathrm{eV})$.

\section{Separation of molecular sidebands}

Certain elements tend to form stable molecules which do not dissociate on ionization. Thus an isotopic purification can be achieved by separating these molecular ions (e.g. $\mathrm{BaF}^{+}$), which are not formed by the respective isobars (no $\mathrm{CsF}^{+}$), rather than the atomic ions. The molecular ion beam is shifted by the mass of the respective ligand to a region 
where often less isobaric background is present. Moreover, for elements where the release time is mainly determined by the desorption of the atoms, a separation as molecules can accelerate considerably the release.

For example, carbon and nitrogen are preferentially separated as $\mathrm{CO}^{+}$and $\mathrm{N}_{2}^{+}$beams respectively. The atomic beams $\mathrm{C}^{+}$and $\mathrm{N}^{+}$are also observed, though with 5 to 10 times lower intensity [41].

Especially many oxides and halides are stable enough at high temperatures to serve as carrier for various elements. Fluorides are preferred among the halides due to their strong binding and the existence of a single stable isotope $\left({ }^{19} \mathrm{~F}\right)$. Chlorides cause an ambiguity in the mass assignment due to the existence of two stable isotopes $\left({ }^{35} \mathrm{Cl}\right.$ and $\left.{ }^{37} \mathrm{Cl}\right)$. Occasionally impurities of the target material or the target container provide enough fluorine to cause significant molecular sidebands. $\mathrm{BaF}^{+}$was observed ten times more intense than $\mathrm{Ba}^{+}$from a molten lanthanum target without additional fluorination [64]. By addition of fluoride vapors to a molten La-Th alloy a ratio $\left[\mathrm{RaF}^{+}\right] /\left[\mathrm{Ra}^{+}\right]>10$ was observed for radioactive radium isotopes at ISOLDE [15]. The ratio of molecular to atomic currents varies strongly with the detailed conditions in the target and ion source unit (see collected literature data in [39]). Still, even if the molecular sideband is weak, it allows to suppress isobaric contaminations and gives a much higher beam purity.

With $\mathrm{CF}_{4}$ addition to an ISOLDE niobium foil target practically elemental pure beams ${ }^{11}$ of neutron-deficient $\mathrm{SrF}^{+}$and $\mathrm{YF}_{2}^{+}$were separated [65]. Earlier at ISOCELE a molybdenum foil target was used to separate $\mathrm{YF}_{2}^{+}$and $\mathrm{ZrF}_{3}^{+}$by fluorine addition [66]. Yttrium fluorides were also separated from a ISOLDE tantalum foil target with an intensity ratio of $\left[\mathrm{YF}_{2}^{+}\right] /\left[\mathrm{YF}^{+}\right] /\left[\mathrm{Y}^{+}\right] \approx 4 / 1.7 / 1$. A significant dependence on the operation conditions of the plasma ion source was noticed. Among the rare earths only lutetium showed considerable fluoride sidebands (as $\mathrm{LuF}^{+}$and $\mathrm{LuF}_{2}^{+}$). Also hafnium trifluoride ions could be separated with a remarkable yield from the tantalum target [23, 65]. This separation method for hafnium isotopes had already been used before at $\mathrm{ISOCELE}^{12}$ [66]. $\mathrm{CaF}^{+}$and $\mathrm{ScF}^{+}$beams were obtained from a fluorinated titanium foil target [65].

Kirchner measured the release profiles and intensity ratios for atomic and monofluoride beams of group IIa and IIIa elements [58]. In all cases the monofluoride beam showed a significant faster desorption and (with a FEBIAD source) a higher current.

Also polyatomic molecular ions can be used as molecular sidebands. $\mathrm{A} \mathrm{SeCO}^{+}$beam from a $\mathrm{ZrO}_{2}$ target was used for chemically pure separation of selenium [23] and enabled the first measurement of the decay properties of the exotic isotopes ${ }^{67,68} \mathrm{Se}[68]$. The homologue $\mathrm{COS}^{+}$beams were not

\footnotetext{
11 The alkali isobars do not form positive fluoride ions, probably due to immediate dissociation when a binding electron gets lost in the ionization process [58].

12 Even $\mathrm{LuF}_{3}$ and $\mathrm{SrF}_{2}$ powder targets were successfully used at ISOCELE for the separation of new $\mathrm{Ta}, \mathrm{Zr}$ and $\mathrm{Sr}$ isotopes as $\mathrm{TaF}_{4}^{+}$, $\mathrm{ZrF}_{3}^{+}$and $\mathrm{SrF}^{+}$respectively [67]. However, these materials are quite volatile and can only be handled with the robust ISOCELE ion sources. The large gas amount would immediately quench the efficiency of the low-current ion sources used at ISOLDE.
}

yet observed at ISOLDE, but in principle the separation as carbonyl ion could open the way to clean sulfur beams. The presently for ISOL facilities inaccessible (so-called "refractory") heavier group VIIA and VIIIA elements could possibly be separated as hydroxides or oxides $[69,70]$, but first an alternative ion source has to be found which is compatible with a high gas load $\left(\mathrm{O}_{2}, \mathrm{H}_{2} \mathrm{O}\right)$.

\section{Other selection methods}

Once the isotopes have left the ion source as ions it becomes much harder to obtain an isobaric separation, but still certain tricks can be applied.

\section{Pulsed release technique}

The release speed of different elements can differ significantly [71]. Thus the various isobars created during the short proton pulse are released more or less rapidly. Opening the beam gate ${ }^{13}$ only for limited time after a well-defined delay, which is optimized for the desired nuclide, allows to improve the signal to background ratio by up to one order of magnitude or more. If the isobaric contaminations have moreover a very short half-life, it is sufficient to wait for their decay before opening the beam gate. Thus, e.g. in the mass range $A=215-218$ the abundantly produced francium and radium isobars with lifetimes in the range of $\mu \mathrm{s}$ to ms can be suppressed completely and the much weaker signals of new exotic lead and bismuth isotopes can be extracted [72].

\section{High resolution mass separator}

In certain cases a high resolution mass separator can be used to separate isobars. Exotic nuclides far from stability have a higher mass excess (which makes them rapidly $\beta$-decay towards stability) than their isobars closer to stability. To resolve the resulting mass difference ( $\Delta M$ typically of the order of $10 \mathrm{MeV}$ ) for medium mass nuclei $(A \approx 100)$ a mass separator with high resolving power $R_{m}>A .931 \mathrm{MeV} / \Delta M \approx 10^{4}$ is required. However, to obtain sufficient resolving power in this "brute force method" it is often required to reduce the beam size by slits, thus compromising the beam intensity.

Up to now the ISOLDE high resolution separator HRS [73] was applied only once ${ }^{14}$ on-line at ISOLDE SC to separate ${ }^{37} \mathrm{Ca}$ from ${ }^{37} \mathrm{~K}$ background [75]. It is presently under recommissioning at ISOLDE PSB.

\section{Conclusion and Outlook}

It is shown that chemistry affects strongly the performance of an ISOL target and ion source unit. Various chemical selection methods were already employed at ISOLDE, but in many cases there is still room for a systematic optimization

\footnotetext{
13 The beam gate is an electrostatic deflector which dumps the ion beam onto a catcher before it can reach the beamline.

14 In subsequent experiments the required selectivity was obtained by separating molecular $\mathrm{CaF}^{+}$beams [74].
} 
of the separation efficiency and beam purity. The extension of the mentioned techniques (mainly molecular separation and the RILIS) could open the way to elements which are presently not accessible by ISOL facilities.

\section{References}

1. Kirchner, R.: Nucl. Instr. Meth. B 70, 186-199 (1992).

2. Schmidt, K. et al.: Nucl. Phys. A 701 (2002), in press.

3. Putaux, J.C. et al.: Nucl. Instr. Meth. B 126, 113-116 (1997).

4. Honig, R.E. and Kramer, D.A.: RCA Review 30, 285-305 (1969).

5. Samsonov, G.V.: The Oxide Handbook. IFI/Plenum, New York (1973).

6. Coating materials and targets, Catalogue. Balzers, Liechtenstein (1994).

7. Ravn, H.L., Sundell, S., Westgaard, L. and the ISOLDE Collaboration: Nucl. Instr. Meth. 123, 131-144 (1975).

8. Bjørnstad, T., Hagebø, E., Hoff, P., Jonsson, O.C., Kugler, E., Ravn, H.L., Sundell, S., Vosicki, B. and the ISOLDE Collaboration: Phys. Scr. 34, 578-590 (1986).

9. Elmroth, T., Hagberg, E., Hansen, P.G., Hardy, J.C., Jonson, B., Ravn, H.L., Tidemand-Petersson, P. and the ISOLDE Collaboration: Nucl. Phys. A 304, 493-502 (1978).

10. Kluge, H.J.: ISOLDE user's guide. CERN Report 86-05, Geneva (1986).

11. Bjørnstad, T., Carraz, L.C., Gustafsson, H.Å., Heinemeier, J., Jonson, B., Jonsson, O.C., Lindfors, V., Mattsson, S. and Ravn, H.L.: Nucl. Instr. Meth. 186, 391-400 (1981).

12. Lettry, J. et al.: Nucl. Instr. Meth. B 126, 170-175 (1997).

13. Kandri-Rody, S. et al.: Nucl. Instr. Meth. B 160, 1-6 (2000).

14. Lau, Christophe: Etude de la production de faisceaux riches en neutrons par fission induite par neutrons rapides. Ph.D. thesis, Université Paris 7 - Denis Diderot (2000).

15. Ravn, H.L.: Nucl. Instr. Meth. 139, 281-290 (1976).

16. Ravn, H.L.: Phys. Rep. 54, 201-259 (1979).

17. Hoff, P., Jonsson, O.C., Kugler, E. and Ravn, H.: Nucl. Instr. Meth. 221, 313-329 (1984).

18. Carraz, L.C., Haldorsen, I.R., Ravn, H.L., Skarestad, M. and Westgaard, L.: Nucl. Instr. Meth. 148, 217-230 (1978).

19. Paris, P., Berg, V., Caruette, A., Obert, J., Putaux, J.C. and Sarrouy, J.L.: Nucl. Instr. Meth. 139, 251-256 (1976).

20. Putaux, J.C. et al.: Nucl. Instr. Meth. 186, 321-328 (1981).

21. Carter, H.K., Kormicki, J., Stracener, D.W., Breitenbach, J.B., Blackmon, J.C., Smith, M.S. and Bardayan, D.W.: Nucl. Instr. Meth. B 126, 166-169 (1997).

22. Eichler, B. and Dressler, R.: Verflüchtigung von Kernreaktionsprodukten aus geschmolzenen Metalltargets. PSI Report 95-03, Paul Scherrer Institut, Villigen, Switzerland (1995).

23. Hageb $\varnothing$, E., Hoff, P., Jonsson, O.C., Kugler, E., Omtvedt, J.P., Ravn, H.L. and Steffensen, K.: Nucl. Instr. Meth. B 70, 165-174 (1992).

24. Vosicki, B., Bjørnstad, T., Carraz, L.C., Heinemeier, J. and Ravn, H.L.: Nucl. Instr. Meth. 186, 307-313 (1981).

25. Oinonen, M. et al.: Nucl. Phys. A 701 (2002), in press.

26. Grawe, H., Hoff, P., Omtvedt, J.P., Steffensen, K., Eder, R., Haas, H. and Ravn, H.L.: Z. Phys. A 341, 247-248 (1992).

27. Bjørnstad, T., Hagebø, E., Hoff, P., Jonsson, O.C., Kugler, E., Ravn, H.L., Sundell, S., Vosicki, B. and the ISOLDE Collaboration: Nucl. Instr. Meth. B 26, 174-182 (1987).

28. Bennett, J.R.J.: Nucl. Instr. Meth. B 126, 105-112 (1997).

29. Drumm, P.V. et al.: Nucl. Instr. Meth. B 126, 121-124 (1997).

30. Benlliure, J., Enqvist, T., Farget, F., Junghans, A.R., Ricciardi, V. and Schmidt, K.H.: In Proc. of the XXXVII Int. Winter Meeting on Nuclear Physics, Bormio, edited by I. Iori. Università degli Studi di Milano (1999).

31. Bergmann, U.C. et al.: Nucl. Phys. A 701 (2002), in press.

32. Beyer, G.J., Knotek, O., Jachim, M., Jushkevič, J. and Novgorodov, A.F.: Nucl. Instr. Meth. 148, 543-551 (1978).

33. Dombsky, M., D'Auria, J.M., Buchmann, L., Sprenger, H., Vincent, J., McNeely, P. and Roy, G.: Nucl. Instr. Meth. A 295, 291298 (1990).
34. Klapisch, R., Chaumont, J., Jastrzebski, J., Bernas, R., Simonoff, G.N. and Lagarde, M.: Phys. Rev. Lett. 20, 743-745 (1968).

35. Thibault-Philippe, Catherine: Etude par spectromètre de masse en ligne de noyaux légers exotiques produits dans les reactions à haute énergie. Ph.D. thesis, Université de Paris (1971).

36. Stearns, C.A. and Kohl, F.J.: J. Chem. Phys. 54, 5180-5187 (1971).

37. Sebastian, Volker: Laserionisation und Laserionenquelle an ISOLDE/CERN. Ph.D. thesis, Johannes-Gutenberg-Universität, Mainz (1999).

38. Carraz, L.C., Sundell, S., Ravn, H., Skarestad, M. and Westgaard, L.: Nucl. Instr. Meth. 158, 69-80 (1979).

39. Köster, Ulli: Yields and spectroscopy of radioactive isotopes at LOHENGRIN and ISOLDE. Ph.D. thesis, TU München (2000).

40. Evensen, A.H.M., Catherall, R., Drumm, P., Duppen, P. Van, Jonsson, O.C., Kugler, E., Lettry, J., Tengblad, O. and Ravn, V. Tikhonov H.L.: Nucl. Instr. Meth. B 126, 160-165 (1997).

41. Ravn, H.L. et al.: Nucl. Instr. Meth. B 126, 176-181 (1997).

42. Ravn, H.L., Bjørnstad, T., Hoff, P., Jonsson, O.C., Kugler, E., Sundell, S. and Vosicki, B.: Nucl. Instr. Meth. B 26, 183-189(1987).

43. Ikeda, N. et al.: Nucl. Instr. Meth. B 70, 150-155 (1992).

44. Barzakh, A.E., Denisov, V.P., Fedorov, D.V., Orlov, S.Yu. and Seliverstov, M.D.: Nucl. Instr. Meth. B 126, 85-87 (1997).

45. Bolshakov, V.A.: Nucl. Instr. Meth. B 70, 69-74 (1992).

46. Hansen, P.G. et al.: Phys. Lett. 28B, 415-419 (1969).

47. Patzelt, P.: The hydroxides of titanium, zirconium, cerium (IV) and thorium for on-line production of noble gases. CERN Report 70-3, Geneva (1970).

48. Maissel, L.I. and Glang, R.: Handbook of Thin Film Technology. McGraw-Hill, New York (1970).

49. Goeminne, G., Wagemans, C., Wagemans, J., Geltenbort, P., Loiselet, M., Gaelens, M., Denecke, B. and Köster, U.: Nucl. Phys. A 688, 233c-236c (2001).

50. Cowan, G.A. and Orth, C.J.: In Proc. 2nd Int. Conf. Peaceful Uses Atomic Energy, Geneva, vol. 7, pp. 328-334. United Nations (1958).

51. Alton, G.D.: Rev. Sci. Instr. 67, 3831-3842 (1996).

52. Dombsky, M. and D'Auria, J.M.: In Applications of Accelerators in Research and Industry, Proc. of the Fourteenth Int. Conf., Denton, edited by J.L. Duggan and I.L. Morgan, pp. 365-368. AIP Conf. Proc. 492, Woodbury, NY (1996).

53. Dombsky, Marik; TRIUMF (Vancouver): priv. comm. (1996).

54. Sundell, S., Ravn, H. and the ISOLDE Collaboration: Nucl. Instr. Meth. B 70, 160-164 (1992).

55. Kratz, K.L., Gabelmann, H., Hillebrandt, W., Pfeiffer, B., Schlosser, K. and Thielemann, F.K.: Z. Phys. A 325, 489-490 (1986).

56. Kirchner, R. and Roeckl, E.: Nucl. Instr. Meth. 133, 187-204 (1976).

57. Langmuir, I. and Kingdon, K.H.: Proc. Roy. Soc. London 107, 6179 (1925).

58. Kirchner, R.: Nucl. Instr. Meth. B 126, 135-140 (1997).

59. Kirchner, R.: Nucl. Instr. Meth. A 292, 203-208 (1990).

60. Ewan, G.T., Hoff, P., Jonson, B., Kratz, K.L., Larsson, P.O., Nyman, G.H., Ravn, H.L., Ziegert, W. and the ISOLDE Collaboration: Z. Phys. A 318, 309-314 (1984).

61. Köster, U.: Nucl. Phys. A 701 (2002), in press.

62. Köster, U. et al.: Hyp. Int. 127, 417-420 (2000).

63. Mishin, V.I., Fedoseyev, V.N., Kluge, H.J., Letokhov, V.S., Ravn, H.L., Scheerer, F., Shirakabe, Y., Sundell, S. and Tengblad, O.: Nucl. Instr. Meth. B 73, 550-560 (1993).

64. Ravn, H.L., Sundell, S., Westgaard, L. and Roeckl, E.: J. Inorg. Nucl. Chem. 37, 383-393 (1975).

65. Eder, R., Grawe, H., Hagebø, E., Hoff, P., Kugler, E., Ravn, H.L. and Steffensen, K.: Nucl. Instr. Meth. B 62, 535-540 (1992).

66. Sauvage, J. et al.: In Proceedings of the TRIUMF-ISOL Workshop, Mont Gabriel, Québec, edited by J. Crawford and J.M. D'Auria, pp. 161-178. TRIUMF, TRI-84-1 (1984).

67. Liang, C.F., Paris, P., Bucurescu, D., Della Negra, S., Obert, J. and Putaux, J.C.: Z. Phys. A 309, 185-186 (1982).

68. Baumann, P. et al.: Phys. Rev. C 50, 1180-1184 (1994).

69. Steffen, A. and Bächmann, K.: Talanta 25, 677-683 (1978).

70. Eichler, B., Zude, F., Fan, W., Trautmann, N. and Herrmann, G.: Radiochim. Acta 61, 81-90 (1993). 
71. Lettry, J. et al.: Nucl. Instr. Meth. B 126, 130-134 (1997).

72. Duppen, P. Van et al.: Nucl. Instr. Meth. B 134, 267-270 (1998).

73. Kugler, E.: Hyp. Int. 129, 23-42 (2001)

74. Garcia, A. et al.: Phys. Rev. C 51, R439-R442 (1995).

75. Garcia, A., Adelberger, E.G., Magnus, P.V., Swanson, H.E., Tengblad, O., the ISOLDE Collaboration and Moltz, D.M.: Phys. Rev. Lett. 67, 3654-3657 (1991). 